\title{
Sex Pheromone Components of the Female Black Cutworm Moth in China: Identification and Field Trials
}

\author{
XIANG Yu-yong ${ }^{1,2}$, YANG Mao-fa ${ }^{1, *}$, LI Zi-zhong ${ }^{1}$ \\ (1. Key Laboratory of Plant Diseases and Pest Management in Mountain Agriculture of Guizhou Province, Institute of Entomology of Guizhou University, \\ Guiyang Guizhou 550025, China; 2. Chemistry and Life-Science Department of Chuzhou University, Chuzhou Anhui 239012, China)
}

\begin{abstract}
The sex pheromone blend of a China strain of the black cutworm moth Agrotis ypsilon (Rottemberg) (Lepidoptera: Noctuidae) was investigated. Chemical analysis of pheromone gland extracts of 3-day-old females showed that individual isolated glands contained only very small amounts of pheromone. The high-resolution gas chromatography combined with mass spectrometry (GC-MS) analysis showed the presence of Cis-7-dodecenyl acetate (Z7-12:Ac, A), Cis-9-tetradecenyl acetate (Z9-14:Ac, B), Cis-11-hexadecenyl acetate (Z11-16:Ac, C), Cis-8-dodecenyl acetate (Z8-12:Ac, E) and Cis-5-decenyl acetate (Z5-10:Ac, D) in biologically active pheromone gland extracts. An extract of one gland from a day 3 female gave the following values for the gland components: $0.245 \pm 0.098 \mathrm{ng}$ for Z7-12:Ac, $0.080 \pm 0.031 \mathrm{ng}$ for Z9-14:Ac, $0.089 \pm 0.033 \mathrm{ng}$ for Z11-16:Ac, $0.085 \pm 0.031 \mathrm{ng}$ for Z5-10:Ac, $0.105 \pm 0.065 \mathrm{ng}$ for Z8-12:Ac per female. The percentages of Z7-12:Ac, Z9-14:Ac, Z11-16:Ac, Z5-10:Ac and Z8-12:Ac in pheromone gland extracts from individual females were $(\operatorname{mean} \pm S E) 40.451 \pm 13.66,13.176 \pm 5.279,14.943 \pm 5.142,14.392 \pm 6.10$ and $17.225 \pm 9.792$ respectively, and the percentages of Z7-12:Ac, Z9-14:Ac and Z11-16:Ac were 58.75 $\pm 9.429,18.91 \pm 7.539$ and 22.34 \pm 7.209 . Field trials indicated that each single component of sex pheromone was non-effective and captured no males. The lures baited with duality compound of $\mathrm{AB}(3: 1)$ had a certain attraction to males, the mean captured number was 2.6. The attraction ability of the lures baited with ternary compound of $\mathrm{ABC}(3: 1: 1)$ to males added significantly, the mean captured number per trap was 7.40 , which was 2.8 times of duality compound of $\mathrm{AB}(3: 1)$. The contents of sex pheromone could obviously affect its capture ability to males, the mean captured number was the highest at the dosage of $200 \mu \mathrm{g}$.
\end{abstract}

Key words: Agrotis ypsilon; Chemical analysis; Field trial; Gas chromatography/High-resolution mass spectrometry; Internal standard; Sex pheromone; Standard chemicals

\section{小地老虎中国种群性信息素的成分鉴定及田间试验}

$$
\text { 向玉勇 }{ }^{1,2} \text {, 杨茂发 }{ }^{1, *} \text {, 李子忠 }{ }^{1}
$$

(1. 贵州大学 昆虫研究所, 贵州山地农业病虫害重点实验室, 贵州 贵阳 550025；2. 涂州学院 化学与生命科学系, 安徽 涂州 239012)

摘要：研究了小地老虎中国种群的性信息素组分, 3 日龄处女蛾单腺体性信息素提取物中性信息素的含量非 常低。GC 和 GC-MS 分析表明, 小地老虎性信息素含有 5 种成分：顺-7-12 碳乙酸酯 (A)、顺-9-14 碳乙酸酯（B)、 顺-11-16 碳乙酸酯（C)、顺-5-10 碳乙酸酯（D）和顺-8-12 碳乙酸酯（E）。它们的含量分别为：（0.245 $\pm 0.098 ） 、$ $(0.080 \pm 0.031) 、(0.089 \pm 0.03) 、(0.085 \pm 0.031)$ 和 $(0.105 \pm 0.065) \mathrm{ng}$, 这 5 种物质的百分比分别为 $40.451 \pm 13.66$ 、 $13.176 \pm 5.279 、 14.943 \pm 5.142 、 14.392 \pm 6.10$ 和 $17.225 \pm 9.792$, 前 3 种物质的百分比为 $58.75 \pm 9.429 、 18.91 \pm 7.539$ 和 22.34 \pm 7.209。田间试验表明, 性信息素单一组分均未诱到雄蛾, AB 以 $3: 1$ 的比例配成的诱芯对雄蛾有一定的引 诱活性, 一个诱捕器平均诱捕到 2.6 头。 $\mathrm{ABC}$ 组分以 $3: 1: 1$ 的比例配成的诱芯对雄蛾引诱活性显著增强, 一个 诱捕器平均诱捕量为 7.40 头, 是 $\mathrm{AB}(3: 1)$ 诱芯的 2.8 倍。诱芯中性信息素的含量对诱蛾活性有明显的影响, 在剂量为 $200 \mu \mathrm{g}$ 时的平均诱捕量最高。

关键词: 小地老虎; 化学分析; 田间试验; GC-MS; 内标; 性信息素; 标准化合物

中图分类号: Q966 文献标识码: A 文章编号: 0254-5853(2009)01-0059-06

\footnotetext{
Received date: 2008-08-11; Accepted date: 2008-12-29

Foundation item: Science and Technology Fund of Guizhou Province (2006-2048)

*通讯作者 (Corresponding author), E-mail: yangmaofa@sohu.com

第一作者（First author): Xiang Yu-yong(1974-), male, doctor, lecturer, E-mail:xyy10657@sohu.com

收稿日期：2008-08-11；接受日期：2008-12-29
} 
The black cutworm moth, Agrotis ypsilon (Rottemberg), belongs to family Noctuidae of Lepidoptera, its common name is soil silkworm, land scissors and roots-cutting worm etc. It is an important cosmopolitan polyphagous agriculture pest, being found in Africa, Asia, Australia, Europe, and North and South America (Rings et al, 1974; Clement et al, 1982; Radcliffe et al, 1991). In China, it distributes in every place of the country, and its host plants are very wide, it can mostly harm 106 kinds of crops, such as vegetables, tobaccos, cottons, corns, broomcorn, hemps and so on (Wei et al, 1989; Zeng, 1994). Due to high resistance to insecticides and nocturnal feeding habits of the larvae, the black cutworm is very difficult to control with insecticides (Han, 1986; Li et al, 2002, 2008). Application of the female-produced sex pheromone provides a promising alternative technique in controlling the pests, and it has been successfully used in population forecasting and mating disruption in many countries (Clement et al, 1981,1982; Willson et al, 1981; Levine et al, 1982; Wakamura et al, 1986). Pioneering work with this species resulted in the identification of two pheromone components Cis-7-dodecenyl acetate (Z7-12：Ac) and Cis-9-tetradecenyl acetate (Z9-14：Ac) (Hill et al, 1979). Recent studies have provided evidence that Cis-11-hexadecenyl acetate (Z11-16: Ac) should be considered a third pheromone component for both a European (Picimbon et al, 1997) and a North American (Gemeno \& Haynes, 1998) population of A. ypsilon. However, there can be a large amount of variability in sex pheromone components and the optimal ratios among components in different geographic populations. Such as Agrotis segetum, a close relative of A. ypsilon, shows geographic variation in pheromone blend composition and male response specificity throughout its area of occurrence (Arn et al, 1983; Löfstedt et al, 1986; $\mathrm{Wu}$ et al, 1999). Therefore, it is very important to start studies on the Chinese black cutworm population. In the present study, the chemical constituents of the sex pheromone gland of the female black cutworm in China were investigated, and individual variations of chemical components in the sex pheromone gland were quantified by gas chromatography.

\section{Material and methods}

\subsection{Insect rearing}

Larvae of A. ypsilon were reared in the laboratory at $(25 \pm 1)^{\circ} \mathrm{C}$ under a $14: 10(\mathrm{~L}: \mathrm{D}) \mathrm{h}$ photoperiod. Larvae before the third instar were reared together for 1-2 weeks and then were reared individually to avoid cannibalism. Male and female pupae were placed in different boxes under the same photoregime and temperature. Pupae were observed every day, and the day on which an adult emerged was taken to be day 0 of adult life. Adult males and females were isolated at emergence, placed in $475 \mathrm{~mL}$ glass containers covered with nylon screen and were provided with $10 \%$ sucrose-water solution.

\subsection{Sex pheromone gland extraction}

The terminal abdominal segments, including the sex pheromone gland, of 25 females ( $3 \mathrm{~d}$ old after emerged) were dissected during the second half of the scotophase, which corresponds with the calling period in this species (Swier et al, 1977; Gemeno \& Haynes, 2000). Fat and other tissues were carefully removed from the inner side of the integument using fine forceps. Individual gland was placed in $1.5 \mathrm{~mL}$ conical bottom glass vials containing $10 \mu \mathrm{L}$ redistilled hexane and 1 ng tridecanyl acetate (13:Ac) as an internal standard. The vials were immediately sealed with Teflon-lined caps and kept for $30 \mathrm{~min}$ at room temperature .Then the glands were taken out and the vials were sealed with spirit lamp, finally, the extracts were stored at $-20^{\circ} \mathrm{C}$ until analyzed.

\subsection{Chemicals}

The standard chemicals Cis-7-dodecenyl acetate (Z7-12:Ac), Cis-9-tetradecenyl acetate (Z9-14:Ac), Cis-11-hexadecenyl acetate (Z11-16:Ac), Cis-8dodecenyl acetate (Z8-12:Ac), Cis-5-decenyl acetate (Z5-10:Ac) and tridecanyl acetate (13:Ac) were purchased from ISCA Technologies, Inc (America).

\subsection{Chemical analysis}

$1 \mu \mathrm{L}$ extract was injected into the gas chromatograph (Hewlett-Packard HP6890GC, Made in Agilent Technologies, State of California, America) equipped with a $30 \mathrm{~m} \times 0.25 \mathrm{~mm}$-ID Carbowax capillary column with a split sample injector(40:1) and a flame ionization detector, connected to a Hewlett-Packard (HP5973, Made in Agilent Technologies) mass selective detector (MSD). Helium was carrier gas. The injector was set at $250^{\circ} \mathrm{C}$ with the purge valve opening $0.75 \mathrm{~min}$ after a manual injection. The oven temperature was held at $80^{\circ} \mathrm{C}$ for $2 \mathrm{~min}$, increased to $290^{\circ} \mathrm{C}$ at $8^{\circ} \mathrm{C} / \mathrm{min}$, and the final temperature was maintained for $2 \mathrm{~min}$. The flow rate of helium through the column was held at $1 \mathrm{~mL} / \mathrm{min}$ and the pressure was $7.62 \mathrm{psi}$. Electron impact (EI) mass spectra were collected at $70 \mathrm{eV}$ with the separator and source at $230^{\circ} \mathrm{C}$.

Each pheromone components were identified by 
comparing their mass spectra with those of authentic standards, and identification was checked subsequently by comparing the GC retention time of the natural product with that of an authentic standard under the same GC conditions as those described above. The quantity of each component was determined by relating its peak area to the internal standard and correcting for the differential responsiveness of the MSD to the compound, which was established daily with the multicomponent standard.

\subsection{Field trials}

Field trials were carried out in March and April, 2007 in a green vegetable producing base at Huaxi, Guiyang. Laver type traps (made from green plastic basin with a diameter of $20 \mathrm{~cm}$ and $10 \mathrm{~cm}$ deep) were used. Traps were filled with water containing $0.2 \%$ detergent and set up in the field $1.5 \mathrm{~m}$ above the ground. Chemicals tested were impregnated into natural rubber septa $(0.9 \times 0.5 \mathrm{~cm})$ and put in the center of the laver trap $1.0 \mathrm{~cm}$ above the water level. Blank traps, traps baited with the extracts from 10 females and hexane were used for comparison. Traps were inspected at $8 \mathrm{O}$ 'clock every morning and the number of males captured were counted and recorded.

\section{Results}

\subsection{Chemical identification}

GC analysis showed 5 peaks in the A. ypsilon gland extract (Fig. 1). The retention times of the five peaks were 11.642, 14.818, 14.750, 17.557 and $20.174 \mathrm{~min}$ respectively. The mass spectra of these 5 components of female tips all gave a fragmentation ion at $\mathrm{m} / \mathrm{z} 61$, indicating that these 5 components are all acetates. By comparing the $\mathrm{GC}$ retention times and spectra of these components with specific synthetic standards, the 5 peaks were identified to be Z7-12:Ac, Z9-14:Ac, Z11-16:Ac, Z8-12:Ac, Z5-10:Ac (m/z, 166, 194, 222, $166,138)$ as shown in Fig. 1.

\subsection{Quantitative analysis}

Tab. 1 shows the amount of sex pheromone components collected from females in midscotophase $($ mean $\pm S E)$. An extract of 1 gland from a day 3 female gave the following values for the sex pheromone components: $0.245 \pm 0.098 \mathrm{ng}$ of Z7-12:Ac, $0.080 \pm 0.031$ $\mathrm{ng}$ of Z9-14:Ac, $0.089 \pm 0.033 \mathrm{ng}$ of Z11-16:Ac, $0.085 \pm 0.031 \mathrm{ng}$ of Z5-10:Ac, $0.105 \pm 0.065 \mathrm{ng}$ of Z8-12:Ac per female. The percentages of Z7-12:Ac,

Tab. 1 Average quantity (ng/female ) of Z7-12:Ac, Z9-14:Ac, Z11-16:Ac, Z5-10:Ac and Z8-12:Ac produced by individual Agrotis ypsilon virgin females that initiated calling at 3 day old, respectively $(n=25)$

\begin{tabular}{|c|c|c|c|c|c|c|}
\hline \multirow{2}{*}{ Number } & \multirow{2}{*}{ Amount of females } & \multicolumn{5}{|c|}{ Contents of sex pheromone components } \\
\hline & & Z7-12:Ac & Z9-14:Ac & Z11-16:Ac & Z5-10:Ac & Z8-12:Ac \\
\hline 1 & 1 & 0.351 & 0.117 & 0.081 & 0.073 & 0.052 \\
\hline 2 & 1 & 0.241 & 0.082 & 0.086 & 0.102 & 0.073 \\
\hline 3 & 1 & 0.192 & 0.076 & 0.089 & 0.068 & 0.251 \\
\hline 4 & 1 & 0.131 & 0.064 & 0.078 & 0.069 & 0.074 \\
\hline 5 & 1 & 0.290 & 0.086 & 0.054 & 0.087 & 0.123 \\
\hline 6 & 1 & 0.453 & 0.079 & 0.167 & 0.051 & 0.099 \\
\hline 7 & 1 & 0.187 & 0.044 & 0.059 & 0.157 & 0.114 \\
\hline 8 & 1 & 0.029 & 0.151 & 0.101 & 0.089 & 0.037 \\
\hline 9 & 1 & 0.228 & 0.097 & 0.12 & 0.09 & 0.075 \\
\hline 10 & 1 & 0.295 & 0.098 & 0.096 & 0.11 & 0.257 \\
\hline 11 & 1 & 0.254 & 0.010 & 0.071 & 0.069 & 0.095 \\
\hline 12 & 1 & 0.365 & 0.062 & 0.094 & 0.086 & 0.072 \\
\hline 13 & 1 & 0.220 & 0.076 & 0.042 & 0.049 & 0.064 \\
\hline 14 & 1 & 0.262 & 0.073 & 0.163 & 0.038 & 0.045 \\
\hline 15 & 1 & 0.117 & 0.085 & 0.053 & 0.160 & 0.229 \\
\hline 16 & 1 & 0.081 & 0.122 & 0.095 & 0.091 & 0.098 \\
\hline 17 & 1 & 0.233 & 0.087 & 0.121 & 0.075 & 0.134 \\
\hline 18 & 1 & 0.401 & 0.027 & 0.149 & 0.103 & 0.035 \\
\hline 19 & 1 & 0.249 & 0.039 & 0.094 & 0.085 & 0.139 \\
\hline 20 & 1 & 0.283 & 0.134 & 0.085 & 0.083 & 0.196 \\
\hline 21 & 1 & 0.199 & 0.078 & 0.089 & 0.058 & 0.058 \\
\hline 22 & 1 & 0.245 & 0.066 & 0.071 & 0.061 & 0.063 \\
\hline 23 & 1 & 0.380 & 0.083 & 0.064 & 0.06 & 0.044 \\
\hline 24 & 1 & 0.251 & 0.081 & 0.057 & 0.142 & 0.065 \\
\hline 25 & 1 & 0.212 & 0.094 & 0.062 & 0.057 & 0.128 \\
\hline Mean $\pm S E$ & & $0.246 \pm 0.098$ & $0.080 \pm 0.031$ & $0.089 \pm 0.033$ & $0.085 \pm 0.031$ & $0.105 \pm 0.065$ \\
\hline$F$ & & 0.40 & 0.39 & 0.37 & 0.37 & 0.62 \\
\hline
\end{tabular}



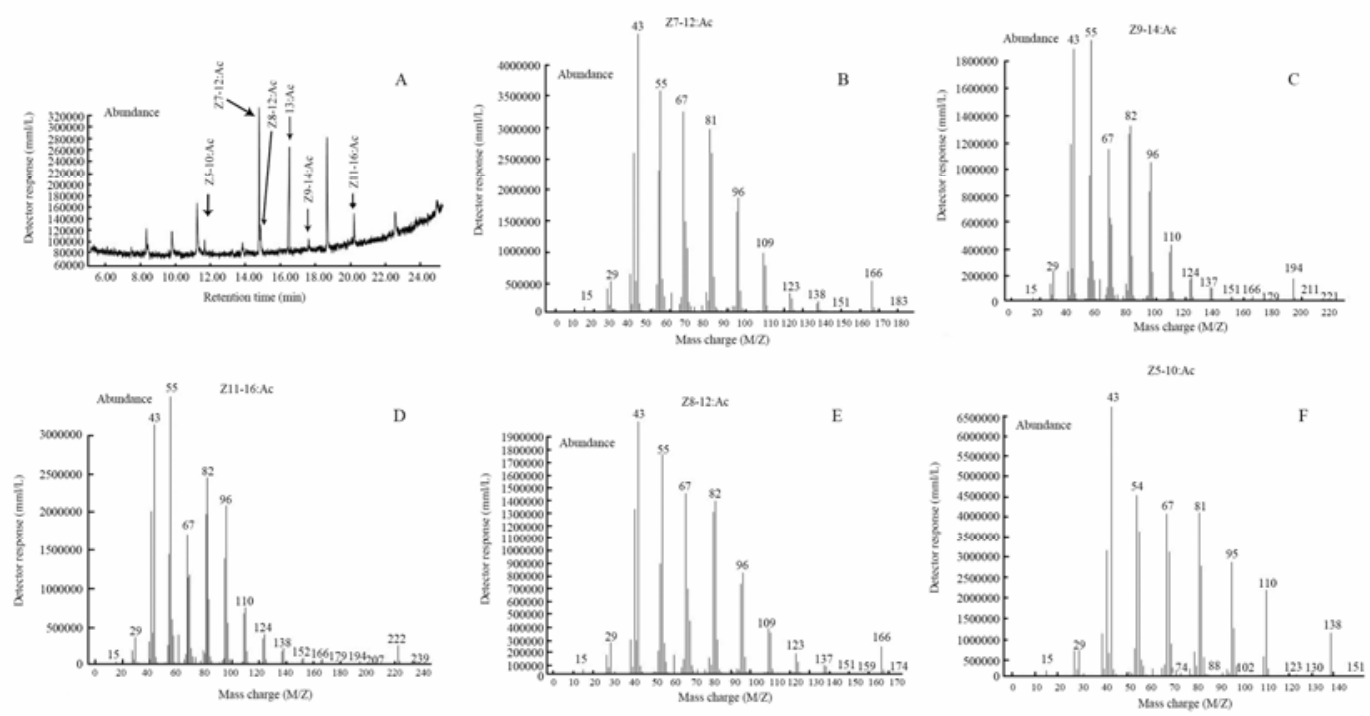

Fig. 1 GC/MS analysis of sex pheromone gland secretion of females from the China population of Agrotis ypsilon A: Total ion current by electron impact of sex pheromone gland extract (10) from 3 day old A. ypsilon females at midscotophase; B: Mass spectrum of sex pheromone component I: Cis-7-dodecenyl acetate (Z7-12: Ac). C: Mass spectrum of sex pheromone component II: Cis-9-tetradecenyl acetate (Z9-14:Ac). D: Mass spectrum of sex pheromone component III: Cis-11-hexadecenyl acetate (Z11-16: Ac). E: Mass spectrum of sex pheromone component IV: Cis-8-dodecenyl acetate (Z8-12:Ac). F: Mass spectrum of sex pheromone component V: Cis-5-decenyl acetate (Z5-10:Ac). Synthetic 13: Ac was the internal standard.

Tab. 2 Percentage of Z7-12:Ac, Z9-14:Ac, Z11-16:Ac, Z5-10:Ac, Z8-12:Ac and Z7-12:Ac, Z9-14:Ac, Z11-16:Ac

\begin{tabular}{|c|c|c|c|c|c|}
\hline & \multicolumn{5}{|c|}{ Percentage of sex pheromone components (\%) } \\
\hline & $\mathrm{Z7}-12: \mathrm{Ac}$ & Z9-14:Ac & Z11-16:Ac & Z5-10:Ac & $\mathrm{Z} 8-12: \mathrm{Ac}$ \\
\hline Z7-12:Ac, Z9-14:Ac, Z11-16:Ac,Z5-10:Ac,Z8-12:Ac & $40.451 \pm 13.66$ & $13.176 \pm 5.279$ & $14.943 \pm 5.142$ & $14.392 \pm 6.10$ & $17.225 \pm 9.792$ \\
\hline Z7-12:Ac, Z9-14:Ac, Z11-16:Ac & $58.75 \pm 9.429$ & $18.91 \pm 7.539$ & $22.34 \pm 7.209$ & & \\
\hline
\end{tabular}

Z9-14:Ac,Z11-16:Ac,Z5-10:Ac and Z8-12:Ac in sex pheromone gland extracts from individual females were $($ mean $\pm S E) 40.451 \pm 13.66,13.176 \pm 5.279,14.943 \pm 5.142$, $14.392 \pm 6.10$ and $17.225 \pm 9.792$ respectively, and the percentages of Z7-12:Ac, Z9-14:Ac and Z11-16:Ac were $58.75 \pm 9.429,18.91 \pm 7.539$ and $22.34 \pm 7.209$ (Tab. 2). From Tab. 1, we can see that the amount of sex pheromone components was different in different females, this owing to the difference between individual females. But this did not influence the calling behavior of the females and the attraction to the males, this indicated that the sex pheromone had a certain active range in the sex pheromone communication system of $A$. ypsilon.

\subsection{The attraction effect of sex pheromone of $A$. ypsilon in the field trails}

The result of field trials was shown in Tab. 3 . From the table we can see that, each single component of sex pheromone was as less effective as hexane and captured no males. Based on the bioassay results in laboratory (published in other paper), we choose the more effective duality compound of $\mathrm{AB}$ (Z7-12:Ac+
Z9-14:Ac) at a ratio of $3: 1$ and ternary compound of ABC (Z7-12:Ac+Z9-14:Ac+Z11-16:Ac) at a ratio of $3: 1: 1$ to proceed the field trial, the dosage of each treatment is $100 \mu \mathrm{g}$. The results showed that the lures baited with duality compound of $\mathrm{AB}(3: 1)$ had a certain attraction to males, and captured 13 males altogether, the mean capture number was 2.6 and the highest number was 4 . The attraction ability of the lures baited with ternary compound of $\mathrm{ABC}(3: 1: 1)$ to males added significantly, and captured 37 males altogether, the mean captured number per trap was 7.40, which was 2.8 times of lure baited with duality compound of $\mathrm{AB}(3: 1)$, and the highest number was 10 . This was significantly higher than that of sex pheromone gland extracts (the mean capture number was 3.40).

\subsection{The effects of sex pheromone dosages on its capture ability to males}

We choose sex pheromone ternary compound of ABC (Z7-12:Ac+Z9-14:Ac+Z11-16:Ac) with a ratio of $3: 1: 1$ at different dosages to proceed the field trial, the results were shown in the table 4 . From the table we can see that, the contents of sex pheromone could 
obviously affect its capture ability to males. When the contents of sex pheromone added, the capture numbers would change significantly. The mean capture number was the highest at the dosage of $200 \mu \mathrm{g}$, captured 11.40 males, and could capture 57 males altogether. The mean capture number at the dosage of $500 \mu \mathrm{g}$ was slightly lower, captured 9.20 males. When the dosage reached $1000 \mu \mathrm{g}$, the mean capture number was the lowest, captured only 2.40 males. So we can conclude that, the best dosage of sex pheromone for capture was around $200 \mu \mathrm{g}$.

Tab. 3 The capture numbers of male Agrotis ypsilon by sex pheromone in the field trial

\begin{tabular}{lcccc}
\hline \multicolumn{1}{c}{ Lures $(100 \mu \mathrm{g} /$ trap $)$} & Seducing time & Total capture numbers & Mean capture numbers (males/trap) & Capture number scopes \\
\hline Z7-12:Ac (A) & $2007.3 .22-2007.4 .6$ & 0 & $0.00 \pm 0.00^{\mathrm{c}}$ & 0 \\
Z9-14:Ac (B) & $2007.3 .22-2007.4 .6$ & 0 & $0.00 \pm 0.00^{\mathrm{c}}$ & 0 \\
Z11-16:Ac (C) & $2007.3 .22-2007.4 .6$ & 0 & $0.00 \pm 0.00^{\mathrm{c}}$ & 0 \\
Z5-10:Ac (D) & $2007.3 .22-2007.4 .6$ & 0 & $0.00 \pm 0.00^{\mathrm{c}}$ & 0 \\
Z8-12:Ac (E) & $2007.3 .22-2007.4 .6$ & 0 & $0.00 \pm 0.00^{\mathrm{c}}$ & 0 \\
AB (3:1) & $2007.3 .22-2007.4 .6$ & 13 & $2.60 \pm 1.14^{\mathrm{bc}}$ & $1-4$ \\
ABC (3:1:1) & $2007.3 .22-2007.4 .6$ & 37 & $7.40 \pm 1.82^{\mathrm{a}}$ & $5-10$ \\
Extracts(10FE) & $2007.3 .22-2007.4 .6$ & 17 & $3.40 \pm 1.15^{\mathrm{b}}$ & $2-5$ \\
Hexane (CK) & $2007.3 .22-2007.4 .6$ & 0 & $0.00 \pm 0.00^{\mathrm{c}}$ & 0 \\
\hline
\end{tabular}

The dates in the table are $\mathrm{M} \pm S E$, the letters after them are the results of multiple comparison. The different letters in the same row means significant difference at 0.05 level, otherwise means no difference.

Tab. 4 The effects of the sex pheromone dosages on the captures of male Agrotis ypsilon

\begin{tabular}{cccc}
\hline Dosages $(\mu \mathrm{g})$ & Total capture numbers & Mean capture numbers (males/trap) & Capture number scopes \\
\hline 50 & 21 & $4.20 \pm 1.30^{\mathrm{d}}$ & $3-6$ \\
100 & 37 & $7.40 \pm 1.82^{\mathrm{bc}}$ & $5-10$ \\
200 & 57 & $11.40 \pm 3.36^{\mathrm{a}}$ & $7-15$ \\
500 & 46 & $9.20 \pm 2.77^{\mathrm{ab}}$ & $5-12$ \\
700 & 24 & $4.80 \pm 1.92^{\mathrm{cd}}$ & $3-8$ \\
1000 & 12 & $2.40 \pm 1.14^{\mathrm{d}}$ & $1-3$ \\
\hline
\end{tabular}

The dates in the table are $\mathrm{M} \pm S E$, the letters after them are the results of multiple comparison. The different letters in the same row means significant difference at 0.05 level, otherwise means no difference.

\section{Discussion}

The sex pheromone blend of A. ypsilon had been reported to be a mixture of Cis-7-dodecenyl acetate (Z7-12:Ac) and Cis-9-tetradecenyl acetate (Z9-14: Ac)(Hill \& Roelofs, 1977; Hill et al, 1979). Several reports indicated that the addition of Cis-ll-hexadecenyl acetate (Z11-16:Ac) to the original 2-component blend increased male captures in Japan (Wakamura et al, 1986), France (Causse et al, 1988), and Ukraine (Buleza,1991). Recently, all three components (Z7-12: Ac, Z9-14: Ac, and Z11-16: Ac) were identified from sex pheromone gland extracts of female A. ypsilon from France, and all three were involved in male attraction as determined from laboratory wind-tunnel tests (Picimbon et al, 1997). French A. ypsilon moths produced Z11-16: Ac in addition to Z7-12:Ac, Z9-14:Ac, Cis-11-tetradecenyl acetate (Z11-14:Ac) and Cis-11-hexadecenol (Z11-16:OH) (Picimbon et al, 1997). However, of all these compounds, only Z7-12: Ac, Z9-14: Ac, and Z11-16: Ac were important in eliciting male attraction in the wind tunnel (Picimbon et al, 1997). Additional components may be involved in the chemical communication system of North American A. ypsilon. These results suggested the existence of some polymorphism among different strains of A. ypsilon throughout the world, in particular, among the European, Asian, and North American populations.

Our GC-MS analysis showed that the sex pheromone gland of the China strain of A. ypsilon contains a multi-component blend consisting of at least five components: Z7-12:Ac, Z9-14: Ac, Zll-16: Ac, Z8-12:Ac, Z5-10:Ac. We proceeded the EAG bioassay experiment and behavior response in a wind tunnel (published in other papers), finding that all these components can trigger EAG response when tested on male antennae of the A. ypsilon, and Z7-12:Ac triggered the largest EAG response. But a ternary mixture of Z7-12:Ac, Z9-14:Ac, and Zll-16:Ac is active in attracting the male moth. Our data support the use of the ternary mixture which has already been used for field trapping (Causse et al, 1988). Z8-12: Ac and Z5-10:Ac are present in gland extracts but may not be involved in attraction of males. Some olfactory neurons tuned to these two components have been detected on the male antennae 
(Renou et al, 1996).

Lack of Z5-10:Ac in the blend does not reduce attraction of the sex pheromone mixture. Z5-12:Ac was recently found to be a fourth sex pheromone component of A. segetutn, (Wu et al, 1995). The presence of sensory cells tuned to Z5-10: Ac in both A. ypsilon and A. segetutn antennae suggests that it could act as an inhibitor of male A. ypsilon. Z5-10: Ac is a powerful antagonist of the peach twig borer pheromone (Millar \& Rice, 1996) and of Coleophora laricella (Priesner \& Witzgall, 1984). The possible presence and the role of this component need to be elucidated in further studies of the sex pheromone communication system between $A$.

\section{References:}

Arn H, Esbjerg P, Bues R, Tóth M, Szöcs G, Guerin P, Rauscher S. 1983. Field attraction of Agrotis segetum males in four European countries to mixtures containing three homologous acetates[J]. Chem Ecol, 9: 267-276.

Buleza VV. 1991. Role of components of sex pheromone in reproductive behavior of male black cutworm (Agrotis ipsilon)[J]. Dokl Biol Sci, 318: $271-273$

Clement SL, Hill AS, Levine E, Roelofs WL. 1981. Trap catches of male Agrotis ipsilon with synthetic sex pheromone emitted from different dispensers[J]. Environ Entomol, 10: 521- 523.

Clement SL, Show ED, Way MO. 1982. Black cutworm pheromone trapping in strawberries[J]. Calif Agric, 36: 20-21.

Causse R, Bues R, Barthes J, Toubon JF. 1988. Mise en evidence expérimentale de nouveaux constituants des phéromones sexuelles de Scotia ipsilon Hüfn. et Mamestra suasa Schiff (Lépidoptères, Noctuidae)[A]. In: Médiateurs Chimiques. Comportement et Systématique des Lépidoptères[C]. Paris: Application en Agronomic. INRA, 75-82

Gemeno C, Haynes KF. 1998. Chemical and behavioral evidence for a third pheromone component in a North American population of the black cutworm moth, Agrotis ipsilon[J]. Chem Ecol, 24: 999-1011.

Gemeno C, Haynes KF. 2000. Periodical and age-related variation in chemical communication system of black cutworm moth, Agrotis ipsilon[J]. Chem Ecol, 26: 329-342.

Hill AS, Roelofs WL. 1977. Sex pheromone of the black cutworm moth, Agrotis ipsilon (Hufnagel) (Lepidoptera: Noctuidae)[J]. N Y Entomol Soc, 85: 179-180.

Hill AS, Rings RW, Swier SR, Roelofs WL. 1979. Sex pheromone of the black cutworm moth, Agrotis ipsilon[J]. Chem Ecol, 5: 439-457.

Han ZJ. 1986. The virulence reaction and fastness variation of the black cutworm to several pesticides[J].Acta Phytophylacica Sinica, 13(2): 125-130.

Levine E, Clement SL, Raster LV, Reaster AJ, Ruesink WG, Showers WB, Turpin FT. 1982. Black cutworm, Agrotis ipsilon (Lepidoptera: Noctuidae), pheromone trapping: A regional research effort[J]. Bull Entomol Soc Am, 28: 139-412.

Löfstedt C, Löfqvist J, Lanne BS, Van der Pers JNC, Hansson BS. 1986. Pheromone dialects in European turnip moths Agrotis segetum[J]. Oikos, 46: 250-257.

Li F, Chen J C, Chen JH. 2002. Effects of Bt on resporation of the larvae of Agrotis ypsilon (Rottemberg) [J]. Natural Enemies of Insects, 24: 15-19.

Li Q, Fan Y, Zhang GA. 2008. Investigation of harming conditions of the ypsilon and $A$. segetum. In $A$. ypsilon the primary long-distance stimulation seems to be due only to the combined action of Z7-12:Ac, Z9-14:Ac, and Zll-16:Ac.

Capillary GC analysis showed that individual sex pheromone glands of $A$. ypsilon contained only a very small amount of material, thus making routine chemical analysis and detection of minor components difficult.

Acknowledgments : The GC-MS analysis was finished in the Key Laboratory of Chemistry for Natural Products of Guizhou Province and Chinese Academy of Sciences, We thank Mr.WANG Dao-ping for helping in carrying out and monitoring mass spectromelry.

black cutworm, Agrotis ypsilon (Rottemberg) and the control of it by insecticide in corn fields of North-West of Qian [J]. Bulletin of Anhui Agriculture Science, 14: 172-173.

Millar JG, Rice RE. 1996. 5-Decyn-1-yl acetate: Powerful antagonist of peach wingborer (Lepidoptera: Gelechiidae) sex pheromone[J]. Econ Entomol, 89: 131-133.

Priesner E, Witzgall P. 1984. Modification of pheromonal behaviour in wild Coleophora laricella male moths by (Z)-5-decenyl acetate, an attraction-inhibitor[J]. Z Angew Entomol, 98: 118-135.

Picimbon JF, Gadenne C, Becard JM, Clement JL, Sreng L. 1997. Sex pheromone of the French black cutworm moth, Agrotis ipsilon (Lepidoptera: Noctuidae): Identification and regulation of a multicomponent blend [J]. Chem Ecol, 23: 211-230.

Rings RW, Arnold FJ, Keaster AJ, Musick GJ. 1974. A worldwide annotated bibliography of the black cutworm, Agrotis ipsilon (Hufnagel)[J]. Ohio Agric Res Dev Cent Res Circ, 198: 1-106.

Radcliffe EB, Flanders KL, Ragsdale DW, Noetzel DM. 1991. Pest management systems for potato insects[A]. In: Pimentel D. Handbook of Pest Management in Agriculture (2nd ed., Vol. III)[C]. Boca Raton, Florida: CRC Press, 587-622.

Renou M, Gadenne C, Tauban D. 1996. Electrophysiological investigations of pheromone-sensitive sensilla in the hybrids between two moth species [J]. Insect Physiol, 42: 267-277.

Swier SR, Rings RW, Musick GJ. 1977. Age-related calling behavior of the black cutworm, Agrotis ipsilon[J]. Ann Entomol Soc Am, 70: 919-924.

Willson HR, Semel M, Tebcherany M, Prostak DJ, Hill AS. 1981. Evaluation of sex attractant and blacklight traps for monitoring black cutworm and variegated cutworm [J]. Econ Entomol, 74: 517-519.

Wakamura S, Struble DI, Matsuura H, Sato M, Kegasawa K. 1986. Sex pheromone of the black cutworm moth, Agrotis ipsilon Hiifnagel (Lepidoptera: Noctuidae): Attractant synergist and improved formulation [J]. Appl Entomol Zool, 21: 299-304.

Wei HJ, Zhang ZL, Wang YZ. 1989. China Underground Pests[M]. Shanghai: Shanghai Science and Technology Press, 276.

Wu WQ, Hansson BS, Löfstedt C. 1995. Electrophysiological and behavioral evidence for a fourth sex pheromone component in the turnip moth, Agrotis segetum[J]. Physiol Entomol, 20: 81-92.

Wu W, Cottrell CB, Hansson BS, Löfstedt C. 1999. Comparative study of pheromone production and response in Swedish and Zimbabwean populations of the turnip moth, Agrotis segetum[J]. Chem Ecol, 25: 177-196.

Zeng ZH. 1994. Plants Doctor Handbook[M]. Beijing: Chemical Industry Press, 218. 